\title{
O DISCURSO PUNITIVO PATERNALISTA BRASILEIRO COMO LEGITIMADOR DA VIOLAÇÃO A DIREITOS HUMANOS - UM PARADIGMA PUNITIVO/RESTRITIVO ÀS LIBERDADES SEXUAIS E REPRODUTIVAS DE GÊNERO
}

\author{
THE PUNITIVE SPEECH AS BRAZILIAN PATERNALISTIC LEGITIMATING \\ VIOLATION OF HUMAN RIGHTS - A PARADIGM PUNITIVE/RESTRICTIVE TO \\ SEXUAL AND REPRODUCTIVE FREEDOMS OF GENDER
}

\author{
Marli Marlene Moraes da Costa \\ Felipe da Veiga Dias ${ }^{2}$
}

\begin{abstract}
RESUMO - A pesquisa em tela visa questionar o discurso penal no Brasil, pautado sob a índole do paternalismo estatal, como forma de violação dos direitos humanos nas questões de gênero. Neste sentido, a crítica centra-se na fragilidade do discurso demagogo mantido na seara criminal, estando em sensível contradição com fundamentos internos, de cunho constitucional e, principalmente, internacional, em matéria de direitos humanos, perpetuando opressões de gênero (especialmente as liberdades sexuais e reprodutivas). Diante disso, a exposição deste tema faz-se imperiosa na construção de um novo pensamento humano-jurídico nacional, o qual busque sempre a igualdade material (entre homens e mulheres) e a justiça social.
\end{abstract}

PALAVRAS-CHAVE - Direitos Humanos e Fundamentais. Gênero. Paternalismo.

ABSTRACT - The research aims to screen criminal questioning discourse in Brazil, based on the nature of state paternalism as a form of violation of human rights in gender issues. In this sense, the criticism focuses on the fragility of demagogic discourse held in criminal harvest, being in contradiction with sensitive internal fundamentals of constitutional nature, and especially in international human rights, perpetuating gender oppression (especially sexual freedom and reproductive). Thus, exposure of this issue it is very important in building a new national legal-human thought, which always seek substantive equality (between men and women) and social justice.

KEYWORDS - Human Rights and Fundamental. Gender. Paternalism.

\section{INTRODUÇÃO}

\footnotetext{
1 Pós-Doutora em Direito pela Universidade de Burgos/Espanha. Doutora em Direito pela Universidade Federal de Santa Catarina, professora da graduação e do Programa de Pós-Graduação em Direito - Mestrado e Doutorado na Universidade de Santa Cruz do Sul. Brasil. Psicóloga com Especialização em Terapia Familiar - CRP n. 07/08955. E-mail: marlicosta15@yahoo.com.br.

${ }^{2}$ Doutorando e Mestre em Direito pela Universidade de Santa Cruz do Sul - UNISC. Especialista em Direitos Fundamentais e Constitucionalização do Direito - PUC/RS. Brasil. Bolsista CAPES. Advogado. E-mail: felipevdias@gmail.com.
} 
O tema proposto por este estudo tem seu foco no debate acerca do discurso penal-punitivo paternalista como forma de manutenção de violação a direito humanos, com atenção diferenciada às questões de gênero. Isso significa que o problema a ser respondido é se dentro de um Estado Democrático de Direito, seguindo-se uma orientação com base nos direitos humanos e fundamentais, podese sustentar a permanência de uma argumentação paternalista para vedar determinadas condutas, com implicações (lesivas) de gênero específico?

A pergunta acima disposta tem um cunho crítico-reflexivo, haja vista que o enrijecimento penal brasileiro, combinado com discursos de recrudescimento punitivo globalizado ${ }^{3}$, pode ser utilizado para conservação de preconceitos históricos (alguns deles superados socialmente) nas temáticas de gênero, estando assim, em franco conflito com alguns direitos humanos.

Destarte, a compreensão do assunto leva necessariamente ao aprofundamento de três enfoques: a) os traços básicos do Estado contemporâneo e as conquistas de gênero; b) a proteção dos direitos humanos e os compromissos em prol da igualdade; c) o discurso paternalista violador de direitos humanos como continuidade punitiva-restritiva de gênero. Estes alicerces serviram, ao final, para a formação do juízo crítico sobre o tratamento deste tema, o qual merece atenção por parte não somente dos operadores jurídicos, mas de toda a sociedade civil.

\section{O ESTADO CONTEMPORÂNEO: CONTRIBUIÇÕES AO DEBATE DE GÊNERO}

O passo inicial deste estudo são algumas considerações sobre o Estado, bem como a associação às questões de gênero que se desenvolveram conjuntamente a este processo. A fase atual do Estado constitucional no Brasil é chamada de Estado Democrático de Direito, caracterizada por contar com um suporte ético e jurídico diferenciado (a Constituição), capaz de gerar efeitos em diversas searas do universo jurídico-social. Isso conduz à imperiosa afetação do campo penal por estes fundamentos constitucionais, visto que nesta seara encontram-se os instrumentos estatais mais poderosos e (potencialmente) mais danosos ao ser humano, merecendo cuidado em sua utilização.

\footnotetext{
${ }^{3}$ No que tange o tema da expansão punitiva criminal, aduz-se a obra de SÁNCHEZ (2011).
} 
Todavia, antes da centralização hodierna do debate, um breve apanhado histórico faz-se contributivo à qualificação da discussão. Por isso o percurso evolutivo dos chamados modelos constitucionais de Estado será o marco inicial, começando pelo Estado Liberal. A espécie aludida veio como uma resposta ao absolutismo, pautando-se sob ideais lluministas, como a liberdade e a igualdade, a fim de opor barreira aos abusos cometidos pelo ilimitado poder do monarca.

Ademais, a soltura das amarras absolutistas tinha uma grande pluralidade de significados e efeitos, dentre os quais se pode mencionar a adoção da tripartição dos poderes, como forma de diluir o poder estatal, bem como o afastamento do ente público das relações privadas, como claro anseio por liberdade. Outras referências poderiam ser feitas, porém a mais relevante foi a conquista de direitos fundamentais. Apesar deste último aspecto positivo, a concepção de igualdade defendida era somente em sentido formal e, além disso, restrita, estando as mulheres alijadas de papel relevante em relação aos homens.

Quanto à percepção dos motivos desta "falta" de prestígio de gênero, cabe recordar razões ancestrais, como as repressões medievais, nas quais as mulheres eram vistas como bruxas, aliadas de satã, o primeiro inimigo da humanidade que não podia ser combatido e, por isso, era atacado através de suas cúmplices ${ }^{4}$. Somados ao aspecto anterior, imputa-se responsabilidade a algumas ideologias religiosas (judaico-cristã) (DIAS, 2004, p. 89 e PIAZZETA, 2001, p. 110 - 113), juntamente até mesmo à parte das ideias iluministas que conduziram os movimentos revolucionários em prol do Estado Liberal, utilizando-se de sociedades maçônicas ${ }^{5}$, as quais não admitiam a inserção feminina em seus escalões, deixando-as apartadas das influências ideológicas da época.

Prossegue-se na caminhada histórica, chegando-se a fase seguinte nomeada de Estado Social; esta teve sua ascensão em decorrência de fatores como: I) a decadência do modelo liberal, o qual obteve crescimento econômico ao mesmo

\footnotetext{
${ }^{4}$ Sobre o combate às mulheres como bruxas, aliadas de demônios, sendo consideradas como os primeiros inimigos da humanidade, pois já que não se podia combater satã, direcionava-se para suas "cúmplices", de maneira que esta pode ser considerada a primeira acepção da teoria do direito penal do inimigo, conferir abordagem de Zaffaroni (2007).

${ }^{5}$ A temática envolvendo a utilização das sociedades maçônicas no período revolucionário francês e na difusão das ideias iluministas está presente na obra de Koselleck (1999).
} 
tempo em que alargou as desigualdades sociais; II) a ocorrência de duas guerras mundiais que desolaram grandes nações; III) crises econômicas (crise de 1929 nos Estados Unidos - Grande depressão); e IV) a crise do positivismo jurídico.

O elenco supramencionado retrata um contexto de abalos variados, ou seja, prejuízos de ordem econômica, ética e jurídica, nutrindo as veias de um novo corpo estatal, o Estado Social. Este trazia consigo o aumento no processo de intervenção (STRECK; BOLZAN, 2001, p. 69), já que seu antecessor havia demonstrado a ineficácia do afastamento extremado entre as esferas pública e privada. Diante disso, objetivava-se reduzir as mazelas sofridas pelos cidadãos (afastando o perfil individualista), pregando concepções compatíveis com uma existência digna e, consequentemente, difundir estes ideais de defesa de direitos humanos e fundamentais por toda a sociedade (PÉREZ-LUÑO, 2005, p. 230).

Outrossim, o sentimento de insatisfação era explícito, levando à total incompatibilidade com um perfil de igualdade formal; desejava-se, sim, a concretização de uma igualdade material, na qual fossem combinados o desenvolvimento individual e social beneficiando toda a sociedade (MIRANDA, 2005, p. 53). Com fulcro neste novo pensamento, em 1948 foi assentada a Declaração Universal dos Direitos Humanos; embora concebida inicialmente como uma fase procedimental dentro do planejamento da Comissão de Direitos Humanos, "esta é uma síntese em que lado a lado se inscrevem os direitos fundamentais ditos de primeira geração - as liberdades -, e os da segunda geração - os direitos sociais" (FERREIRA FILHO, 1998, p. 53).

Cabe menção, diante de sua relevância a partir desta etapa histórica, ao movimento feminista, o qual ganhou fôlego no final do século XIX e início do século $X X$, defendendo a paridade sobre diversos direitos fundamentais já garantidos aos homens, no entanto cerceado das mulheres, tais como a autonomia, propriedade, integridade do corpo, dentre outros (COSTA, 2011, p. 197). Ademais, o citado movimento ofertou enfoque crítico à própria estruturação da sociedade, de cunho patriarcal (PIAZZETA, 2001, p. 110), mantido durante muito tempo e ainda demonstrando seus resquícios ao restringir a posição da mulher no acesso aos meios de produção, a direitos humanos e fundamentais ou até mesmo entendendo 
que estas ainda teriam como função mais importante a reprodução e não a participação igualitária na sociedade.

Não obstante, existe a possibilidade de um parêntese relevante ao debate, pois diz respeito aos fundamentos utilizados na confecção de determinadas incriminações (de cunho de gênero), mais precisamente, a conotação da codificação criminal datada do ano de 1940 (ZAFFARONI, 2007, p. 102 e JAKOBS, 2010) que veda, até os dias de hoje, muito a liberdade de homens e especialmente de mulheres, com bases no fascismo italiano e ao mesmo tempo de concepções eugênicas (segregação de minorias) ${ }^{6}$. Embora possa parecer pouco relevante essa alegação diante das possibilidades hermenêuticas, uma reanálise conforme os ditames constitucionais revela marcas do passado que ainda são aplicadas, tão somente mascarando-se os argumentos a fim de legitimar o abuso do Estado.

Retomando-se o pensamento anterior, os movimentos sociais, como o feminista, contribuíram em grande monta para o crescimento humano-social na modernidade. Apesar do Brasil não ter vivido os dois modelos anteriores em sua integralidade, pode-se aludir que uma amostra da importância desses movimentos foram as colaborações ofertadas pelo feminismo durante 0 processo de redemocratização do país, o qual convergiu juntamente com a etapa subsequente no desenvolvimento estatal, qual seja, o Estado Democrático de Direito.

A carta constituinte de 1988 alinhavou um novo suporte axiológico para a sociedade brasileira, detendo força modificativa e materializadora de direitos, recrudescido em comparação com o modelo social, visando fundar fortes alicerces éticos, democráticos e jurídicos para refutar claramente o recente período de exceção (ditadura militar) (BONAVIDES, 2004, p. 324) e enaltecer a relevância da Constituição como matriz jurídica e social.

Com a finalidade de reconstruir os marcos jurídicos, sociais e os próprios rumos do país, o texto constitucional veio impor a sua supremacia, reascendendo a chama do direito como ciência interpretativa aberta, capaz de irradiar os efeitos

\footnotetext{
${ }^{6} \mathrm{Na}$ obra seguinte encontra-se um panorama não somente europeu e norte-americano, mas principalmente a ótica da América Latina, a qual fez uso dos fundamentos eugênicos para sustentar diversas intervenções estatais sob a bandeira da higienização, tendo, inclusive, mantido tal postura em alguns casos, mesmo após a refutação destes fundamentos no período pós-segunda guerra mundial. Miranda (2005).
} 
constitucionais para toda a legislação vigente e a ser construída (SILVA, 2005, p. 41 - 43). Resumidamente, a Constituição de 1988 marca a chegada do modelo democrático de direito ao Brasil, com a soma contributiva de movimentos sociais (como o feminista) na sua elaboração, resguardando uma série de direitos e garantias fundamentais a todos os cidadãos, sejam eles homens ou mulheres.

\section{OS DIREITOS FUNDAMENTAIS E HUMANOS EM RELAÇÃO ÀS QUESTÕES DE GÊNERO: ALINHAMENTO INTERNO/INTERNACIONAL}

Antes de iniciar a abordagem da influência dos direitos humanos, cabe uma breve ressalva, visto que se tocou em duas expressões, "direitos fundamentais" e "direitos humanos", entendendo-se a distinção entre os dois termos da seguinte forma: os direitos humanos estão previstos na órbita internacional, enquanto que aqueles nomeados como fundamentais são previstos internamente, com a finalidade de dar maior efetividade aos anteriores (SARLET, 2009, p. 29).

Diante disso, quando se procura tratar interesses como a igualdade ou a liberdade, conforme se pode reconhecer na essência dos debates a serem travados, mesmo que em sentido específico no debate de gênero, percebe-se a dupla inserção destes argumentos, ou seja, existe a coalizão entre a proteção dos direitos humanos, de cunho mais amplo, e dos direitos fundamentais, para efetivar o necessário resguardo desses direitos.

Delimitada a diferenciação inicial traz-se a priori alguns aspectos internos e posteriormente outros de cunho internacional. Assim, o atual sistema jurídico nacional baseia-se em um pensamento interpretativo moderno fundado sob bases ético-jurídicas (índole pós-positivista) (BARROSO, 2006, p. 26 - 27), guardando vínculos com a hermenêutica filosófica (giro-linguístico), a qual invadiu a interpretação constitucional hodierna, valorizando a linguística, a compreensão (précompreensão do indivíduo, somada à interpretação/aplicação para alcançar a real compreensão sobre algo), o diálogo e o papel do jurista no processo de interpretação (GRONDIN, 1999, p. 186 e GADAMER, 2005, p. 355).

Essa visão interpretativa oportuniza novo enfoque aos princípios constitucionais como a dignidade humana, a qual passou a ter papel de destaque no 
cenário interno e internacional, neste último, em especial após o período da $2^{\mathrm{a}}$ guerra mundial, onde se carecia de renovações nos suportes valorativos do direito (superação da neutralidade positivista). Este princípio (e fundamento da República) irradia seus efeitos a todo o ordenamento jurídico, constituindo-se em norte a ser seguido (CANOTILHO, 2004, p. 225). Previsto em grande parte dos textos constitucionais no período pós-guerra, a dignidade humana detém um alto grau de abstração, porém, isso não impede a sua compreensão de fundamento protetor do ser humano como indivíduo, respeitado, único em sua existência, afastando qualquer tratamento do homem como objeto (influência da concepção kantiana) (SARLET, 2008, p. 37) ${ }^{7}$.

A impossibilidade de formatação de um conceito em nada reduz a importância deste baluarte do direito contemporâneo, sendo mais fácil identificar uma violação a ele do que propriamente os seus contornos. Igualmente, compactua-se do entendimento de que os princípios constitucionais (e muitos dos direitos humanos) são descendentes de uma matriz e, essa seria a dignidade humana (SARLET, 2008, p. 83), fato este que gera, consequentemente, uma ofensa indireta em caso de lesão ao outros direitos humanos e fundamentais (ou princípios), pois esses mandamentos originados na dignidade têm o condão de materializar os valores nela contidos.

Há aqui um apontamento a ser realizado a respeito de construções dogmáticas da dignidade humana, as quais mesmo com a dificuldade conceitual são capazes de perceber funções específicas, tais como a função limitadora e prestacional. A primeira espécie apresenta condão negativo, no sentido da restrição de ações entre particulares e do próprio poder estatal, já a segunda expõe ângulo positivo, buscando a concretização de uma existência digna ao ser humano (CARVALHO, 2007, p. 294 - 295). A partir da orientação assimilada na classificação supra este estudo foca sua análise na função negativa, visto que esta face restringe ações estatais, para com isso evitar condutas abusivas por parte do ente público sobre os cidadãos.

Contudo, existem outros direitos e princípios que podem facilitar a compreensão das questões a serem debatidas no contexto dos conflitos de gênero,

\footnotetext{
${ }^{7}$ Em igual sentido a posição de Rodriguez (2007. p. 45-46).
} 
por tratarem de enfoques mais específicos, já que a alegação da dignidade humana muitas vezes beira o vácuo argumentativo. Explica-se, na maior parte das situações fáticas podem ser encontrados mandamentos constitucionais específicos, os quais são ramificações da dignidade humana, como forma de especializar o seu ensejo. Sendo assim, há aqui a necessidade de encorpar o conteúdo deste debate, sob pena de alegação distante da realidade.

Neste desiderato, dois ideais, considerados inestimáveis desde os tempos da Revolução Francesa, são perceptíveis na delimitação desta pesquisa, a igualdade e a liberdade. A primeira é de fácil observação, já que o viés dado até o momento externou que a concretização da igualdade vem sendo construída com o passar dos anos, progredindo de um viés inicialmente formal para busca por um perfil material. Somente com esta nova ótica pode-se cogitar o desenvolvimento de uma sociedade justa e digna a realmente todos, conforme externa as palavras de Naele Ochoa Piazzeta $(2001, \text { p. } 85)^{8}$ :

O princípio da igualdade não é acionado sozinho quando a questão diz respeito a homens e mulheres. Os princípios da dignidade e da tolerância também devem ser chamados ao debate, uma vez que inclui as diferenças pessoais sociais. Reside ela no valor associado de maneira não diferenciada a todas as pessoas, sem distinção de sexo, raça, crença, de modo que seu valor está no fato de que todas as diferentes identidades fazem de cada pessoa um indivíduo diferente dos demais e de cada indivíduo uma pessoa como todas as demais.

Na segunda alegação, a liberdade que se refere conduz à ideia de autonomia, ou seja, o indivíduo regrando sua vida, sem intervenções estatais, a não ser em caso de prejuízo a terceiras pessoas. Sabe-se, contudo, que autores debatem se a nomenclatura atual seria autonomia da vontade ou privada, no entanto, tal debate não interessa aos fins aqui pretendidos (FARIA, 2007, p. 60 - 62).

Os pilares indicadores da liberdade e da igualdade são obrigatórios ao entendimento do debate de gênero, haja vista que estes atuam combinadamente para concretização de direitos. Todavia, retomando especificações da dimensão negativa da dignidade humana, aduzem-se reflexões da conexão constitucional penal orientadora na atividade legislativa e judicial (BITENCOURT, 2003, p. 09 -

\footnotetext{
${ }^{8}$ Complementa o pensamento de Ferrajoli (2010).
} 
10), referente ao princípio da ofensividade. Isso significa que juntamente às concepções de igualdade e liberdade, soma-se no raciocínio a concepção da ofensividade, a qual versa que inexiste uma conduta criminosa sem um dano efetivo ou perigo (de lesão) a um interesse (bem) jurídico relevante (nullum crimen sine iniuria) (GOMES, 2002, p. 14).

O referido princípio serve como uma barreia a inibir a criação de tipos penais (fato ofensivo típico) descabidos (inconstitucionais) pela ausência de um bem jurídico (ROXIN, 2009, p. 18) (relevante) a ser protegido ou a simples falta de afetação do bem jurídico alheio (em algumas incriminações paternalistas há lesão a bem jurídico próprio).

Até aqui foram sintetizados os principais fundamentos teóricos na órbita interna, apesar de que ideais como liberdade e igualdade são defendidos declaradamente na esfera internacional, havendo a duplicidade protetiva - direitos fundamentais e humanos - na efetivação desses direitos, devidamente somados a um pensamento constitucional penal, orientado pela ofensividade.

Entretanto, por meio da adição contributiva internacional em matéria de direitos humanos far-se-á o fechamento desta etapa. A preocupação brasileira acerca dos conflitos de gênero sofreu influências externas, pois a percepção global de problemas de discriminação, falta de oportunidades, segregação, violência contra a mulher, foi sendo colocada em evidência, conforme comentam os diversos documentos elaborados desde a década de 70, com objetivo dar fim a estas violações (PIOVESAN; GONÇALVES, 2011, p. 376).

Portanto, a efetiva proteção feminina, em prol de um modelo diferenciado de igualdade, originou a formação de novas construções a partir da matriz da dignidade humana; dentre essas possibilidades há o princípio da autonomia reprodutiva, o qual liga noções de dignidade, igualdade e liberdade, visando à proteção paritária de homens e mulheres (SARMENTO, 2006, p. 111 - 168 e DIAS, 2004, p. 95). Externa com precisão a luta por direitos deste calibre a autora Flávia Piovesan (2007, p. 66), ao referir o princípio acima aludido, juntamente à seguridade de procedimentos abortivos às mulheres (luta em prol da legalidade do aborto), em documentos internacionais. 
No plano jurídico, a criminalização do aborto viola os chamados direitos sexuais e reprodutivos das mulheres, amparados pela Conferência Internacional sobre População e Desenvolvimento do Cairo de 1994, bem como pelas Conferências de Copenhagem de 1994 e de Pequim de 1995. A criminalização do aborto resulta, assim, como uma violação a direitos humanos internacionalmente protegidos, em particular nas esferas da sexualidade e reprodução.

Embora existam manifestações nesse sentido, tal princípio ainda não vem surtindo efeitos internamente em resoluções de embates nacionais, porém, a discussão iniciada em 2004, acerca do aborto de feto anencéfalo ainda não obteve solução em sede de jurisdição constitucional (Supremo Tribunal Federal) (PIOVESAN; GONÇALVES, 2011, p. 378 - 382), podendo ser um caso para menção deste novo fundamento de gênero. Mesmo que em determinadas situações não se verifique a aplicação concreta de visões principiológicas de direitos humanos no âmbito interno, também há casos de progresso devido à pressão internacional, conforme foi a notória Lei Maria da Penha, na direção de coibir a violência contra mulher.

A apresentação de duas tendências diferentes visa demonstrar que não se prega qualquer política anti-Estado, muito antes pelo contrário, deseja-se que o modelo democrático brasileiro siga a influência positiva dos direitos humanos previstos internacionalmente, convergindo para efetivação de direitos inerentes ao desenvolvimento humano digno. Contudo, para alcançar um patamar diferenciado é necessário o questionamento de determinados fundamentos que sustentam, por vezes, normas jurídicas incompatíveis com o pensamento contemporâneo, seja em matéria constitucional ou internacional, levando desse modo a questionar determinados "crimes", os quais podem somente servir à manutenção do status violador, como no caso das restrições de gênero.

\section{O DISCURSO PATERNALISTA, VIOLADOR DE DIREITOS HUMANOS, COMO CONTINUIDADE PUNITIVA-RESTRITIVA DE GÊNERO.}

Nesta última etapa os fundamentos relatados convergem na direção da apreciação do tema específico, faltando apenas alguns elementos nessa equação, mais precisamente, a compreensão dos limites à intervenção estatal, amparados nos termos dos direitos humanos e na Constituição, associando o pensamento 
constitucionalizado da ótica penal e o respeito à concepção moderna de igualdade de gênero. Os limites mencionados conduzem, no modelo democrático, efeitos de ações condicionadas, ou seja, existe o dever de efetivar os direitos fundamentais trazidos no texto constitucional e, para isso, deve-se utilizar-se de todas as ferramentas necessárias, sem abusos de poderes. O poder coercitivo do ente público se legitima não somente pela força, mas pela corroboração política (CADEMARTORI, 1999, p. 91), ou seja, a legitimidade constitucional soma-se à política para legitimar o Estado a intervir.

Seguindo essa linha de raciocínio, observa-se uma série de restrições ao uso do poder, seja pela liberdade, igualdade ou por outros princípios, pois de acordo com a pressuposição esculpida pela ofensividade a ilicitude encontra-se no dano ou perigo a terceiro, resguardando a esfera da autonomia decisória do indivíduo e permitindo que este faça tudo que não estiver proibido (vinculação a legalidade). Todavia, podem ocorrer abusos dos instrumentos coercitivos por parte do Estado (já que existe uma considerável expansão dos meios punitivos) (ANDRADE (B), 2003, p. 25), levando a medidas autoritárias ou ações de cunho paternalista.

Nos dois casos citados estão presentes abusos por parte do Estado, no entanto, as ações de cunho paternalista têm característica diferenciada da autoritária, já que está última não respeita qualquer embasamento, violando a legislação e ultrapassando barreiras no exercício do poder, diferentemente da segunda que visa à proteção do indivíduo contra suas próprias ações, restringindo a possibilidade de autolesões. No paternalismo há censura do comportamento, tratando um adulto como uma criança, negando a ele a sua autonomia de decidir; a questão é que se quer referida proteção, mas não por vias de um posicionamento antiliberal (extremo), até mesmo porque, muitas vezes tal ato compõe-se de atributos morais ou religiosos impostos para viciar/deturpar o desejo alheio.

Não existe uma pressuposição negativa na utilização da terminologia, visto que esse conceito também comporta a defesa de pessoas consideradas vulneráveis ou sem capacidade para se proteger por suas próprias forças (FEINBERG, 1986, p. 05), demonstrando que existem ações com tal sustentação dentro dos parâmetros dos direitos humanos e fundamentais, regendo-se por ideais de proteção do ser humano em sua individualidade (resguardo de pessoas mais vulneráveis). 
Contudo, o cerne de aversões reside nas ações inseridas na primeira face do conceito, por terem em grande parcela se sustentado em reprovações religiosas ou morais e, tal índole não pode ser compactuada, não somente pela ofensa a princípios constitucionais (por exemplo, igualdade, ofensividade) ou a direitos humanos, mas por ser inconcebível uma moral geral (imposta) a toda coletividade.

Isso significa, em regra, que o Estado tem legitimidade para intervir na esfera individual do ser humano quando suas ações levarem à lesão (ou perigo) a outrem, mas não quando estas representarem um dano contra si mesmo (MILL, 2002, p. 08). A defesa de conteúdo de autonomia condutiva na vida do indivíduo não obsta argumentações em contrário, já que se conhece a existência de decisões estrangeiras em sentido diverso (nesse sentido o conhecido caso do arremesso de anões - ocorrido na França) (VERÍSSIMO NETO, 2010), apresentando como uma exceção ao respeito da livre condução da vida os casos em que ações individuais ofendem ou denigrem a essência humana.

Compreendidos os contornos da concepção de paternalismo, não se pode furtar em mencionar que este instituto possui classificações tendo em vista os aprofundamentos teóricos despendidos em torno do tema; no entanto, inexiste espaço hábil para trabalhar toda a gama construída doutrinariamente, atendo-se aqui àquela considerada mais importante para o posterior entendimento. Dito isto, existe divisão teórica entre o paternalismo direto, concebido no envolvimento de apenas uma pessoa, por exemplo, no suicídio; e o paternalismo indireto, caracterizado pela participação de mais de um indivíduo, como se visualiza na eutanásia.

Considerando-se, contudo, a inserção desses aspectos num Estado de Direito que prima pelo respeito aos direitos humanos, fundamentais e valores individuais do ser humano, cabe referir uma última possibilidade de exceção, a qual faria do paternalismo estatal uma condição suportável, nesse caso (justificando, assim, a nomeação de paternalismo limitado). Sob determinadas circunstâncias, mesmo contra a vontade do indivíduo legitima-se a intervenção estatal; prova disso é a insanidade temporária, quando a ação interventiva se dá na intenção de proteger o indivíduo de ações autolesivas, pressupondo (arrazoadamente) seu provável arrependimento assim que restabelecida a plenitude de suas faculdades mentais. 
Estes procedimentos revelam-se compatíveis com os valores protegidos pelos direitos humanos e pelo texto constitucional brasileiro, pretendendo resguardar o cidadão. Porém, na busca pela materialização deste anseio protetivo, em diversos momentos exorbita-se tais poderes, como se vislumbra em algumas intervenções paternalistas.

A ligação dos pontos relatados até aqui se ampara na perspectiva constitucionalizada do direito, em especial na esfera criminal, tendo em vista ser este o mecanismo mais poderoso nas mãos do Estado. Portanto, por mais bem intencionadas que estejam as ações estatais, estas podem violar limites de direitos humanos e fundamentais ou princípios constitucionais (dignidade, liberdade, igualdade, ofensividade), fazendo de tais ferramentas punitivas (que se pretendem protetivas) simples instrumentos simbólicos de repressão. Junto a essa ótica somam-se os fatores históricos e sociais, principalmente em relação às questões de gênero, haja vista a morosidade do processo de equiparação entre homens e mulheres, bem como a perpetuação de um tratamento diferenciado, mas não em sentido positivo - veiculando desigualmente os desiguais - e sim negativo, dando continuidade ao alijamento de parcela significativa das atrizes sociais brasileiras (opressão de gênero).

Ante tal panorama, utilizar-se-ão duas exemplificações de restrições penais, fundadas em um discurso paternalista moralista (ou religioso), servindo de substrato à manutenção fora dos limites legais de certas ações, determinando a constância na violação a direitos humanos e fundamentais de diversas mulheres no Brasil. $O$ primeiro "delito" é o aborto, o qual costuma contar com argumentos apaixonados de várias facções religiosas, no entanto, contumazmente sem qualquer parâmetro jurídico a sustentar seus argumentos.

A situação em comento possui em sua essência um discurso paternalista religioso e moral, afirmando o que seria a melhor decisão para mulher, sem levar em conta qualquer parâmetro contrário (demais direitos humanos e fundamentais envolvidos). Percebe-se o desprezo completo do elemento volitivo da mulher, rumando na direção dos entraves históricos (modelo patriarcal e machista), bem como nem se cogita a integração da autonomia reprodutiva como um elemento a ser 
considerado, reduzindo o papel dos direitos humanos na busca da igualdade fática (SARMENTO, 2006, p. 113).

Não obstante, soma-se a esta tentativa de condução moral o fator econômicosocial, obtendo como "público alvo" desta conduta mulheres de classes menos abastadas, em outras palavras, somente aqueles que não podem driblar os mecanismos coercitivos, lesando uma faixa determinada de indivíduos com menores condições financeiras e já prejudicados socialmente (ANDRADE (A), 2003, p. 270).

Apenas como menção, existe o entendimento de que o equívoco no tocante à análise do aborto residiria na sua abordagem, pois vê-lo como um delito seria um erro, o qual somente seria sanado no momento em que se passasse a identificá-lo como uma questão social, ou ainda como um problema de saúde pública. A ineficácia dos meio punitivos para coibir a conduta, associada à falta de apreço pelos direitos femininos na análise, convergem à demonstração da fragilidade do discurso que suplanta a sua manutenção (comprovado pelo número de abortos ilegais).

A modificação no tratamento da questão priorizando a harmonia entre os interesses de gênero e os demais direitos humanos e fundamentais poderia levar à resolução da situação nas vias da saúde pública, obviamente pela afetação em sua grande maioria da camada pobre da população, a qual não teme a ilicitude do fato (fator de extrema relevância na ótica penal) e o pratica em condições precárias (desumanas - ofensa à integridade mínima do ser humano), podendo levar à morte das gestantes, a diversas infecções ou doenças (TORRES, 2007, p. 31). Não bastassem estes argumentos, apenas como observação valorativa, o número de denúncias é baixo, não diferindo das condenações pelo delito em quantidade ínfima ou até mesmo considerada irrelevante, demonstrando-se uma conivência não somente das autoridades punitivas, mas da própria sociedade com a prática delituosa. Deste modo, apesar de restrições individuais morais ou religiosas, o tratamento criminoso desta conduta não coaduna nem com o pensamento constitucional penal, tampouco com a realidade social (BARSTED, 2007, p. 98).

A partir dos enfoques aludidos, não obstante a comprovação de viabilidade, inclusive econômica deste último fundamento (tratamento da questão em sede de saúde pública) (SARMENTO, 2006, p. 157 - 158), objetiva-se criticar o paternalismo 
que sustenta tal "delito", amparando-se na racionalização entre o custo e o benefício da incriminação, além dos parâmetros de direitos humanos e fundamentais.

Isso reflete que ao invés de debater efetivamente o tema, como foi feito nos Estados Unidos (DWORKIN, 2003, p. 05 - 09) ou na Alemanha (SCHWABE; MARTINS, 2005, p. 266 - 294), tem-se uma discussão em escala reduzida, ou seja, no Brasil tão somente pretende-se discutir o caso da interrupção da gravidez de feto anencéfalo (conforme decisão ainda em debate no Supremo Tribunal Federal), ofertando pouca relevância à questão geral, para ater-se a uma especificidade. Não se está aqui a criticar a posição jurisdicional, já que esta se manifesta tão somente acerca daquilo que é questionada, e sim se repugna a postura geral do Estado, ao manter um discurso demagógico como base de impedimento dos direitos humanos e fundamentais de gênero (autonomia reprodutiva, igualdade, etc.)

O acaloramento dos ânimos na questão do aborto não se coaduna com a próxima demonstração, todavia, isso não significa uma menor valia pelas chamadas casas de prostituição. Nesta situação, o revestimento de um discurso moral paternalista, com base repressiva, é evidente, porém, o círculo no entorno aos fatos deixa ainda mais clara a problemática, mais precisamente, os poderes estatais (especialmente o Legislativo) simplesmente desprezam as atividades ligadas ao sexo (justificativa moral para omissão), asseverando-se tal afirmativa pela ausência de regulamentação profissional às prostitutas, dançarinas, atrizes (ou atores) pornográficos, dentre outros.

O contexto retratado induz à consequente incriminação das casas de prostituição, mesmo que a atividade de prostituir-se não seja ilícita, a conduta de fornecer local à prática de prostituição é reprimida pelo ente público.

Há valoração da ação de forma negativa pelo componente moral, já que a atividade em si não oferece periculosidade social, todavia, a sua punição se dá com força máxima dentro do ordenamento jurídico visando impedir outras pessoas de seguirem o mesmo caminho "imoral", impondo com isto um freio ao livre arbítrio (autonomia), com uma medida paternalista (ESTELLITA, 2007, p. 18). A ofensa aos cidadãos é plural, pois atinge o cliente, a prostituta e aquele que a abriga na disposição de sua autonomia (liberdade) e sem que ocorra uma ofensa justificável 
(lesão ao princípio da ofensividade), como uma lesão patrimonial ou algo semelhante, sem a cogitação de uma solução menos gravosa aos envolvidos.

Além da contradição interna comentada, a postura estatal brasileira leva a um processo dedutivo simples e ao mesmo tempo ilógico. Explica-se, a proibição do abrigo das pessoas praticantes da conduta joga esses homens e mulheres (em sua maioria) a trabalhar nas ruas, onde são alvo da criminalidade e ao mesmo tempo são postos em condição de vulnerabilidade, estando, por conseguinte, o presente posicionamento, em franca oposição ao caminho em prol da defesa dos direitos humanos de gênero (afetação de mulheres em maior grau), ao colocar estas pessoas nas mãos da violência urbana.

Acrescenta-se à equação crítica a conivência da sociedade com a conduta, pois além da realidade social compor o processo hermenêutico contemporâneo (leitura constitucional-penal), estes locais são notórios em seu exercício, sob qualquer nomenclatura (exemplo: bar, sauna, wiskeria, casa de shows), sem que ocorra qualquer procedimento do Poder Público ou manifestação de repúdio popular, inexistindo fundamento plausível à manutenção da conduta na ilicitude ( $\mathrm{NUCCl}$, 2007, 853 - 854) (ou de outro modo, inexiste fundamento plausível que não se ampare em concepções marcadamente, senão exclusivamente, de cunho moral). Até mesmo porque, conforme citou-se anteriormente, a vedação de abrigo conduz à exposição dessas pessoas aos riscos das ruas, as quais são extremamente perigosas no período noturno (quando se dá o ápice da atividade e da criminalidade), lesando duplamente direitos humanos e fundamentais.

Assim, apresentam-se diversas incoerências denotando o equívoco no uso dos meios penais para coerção paternalista penal (VON HIRSCH, 2007, p. 20 - 22), cogitando-se soluções em outros ramos do direito ou da própria sociedade. O levantamento deste crime como uma opressão de gênero (pois reprime com certa especificidade mulheres) tem guarida em um duplo argumento, o primeiro é quantitativo, haja vista que a prática da prostituição se perpetua em maior quantidade entre mulheres, já o segundo é de ordem constitucional-penal, visto que tal crime reprime a autonomia feminina (ferindo uma série de princípios já aludidos), buscando impor uma orientação moral, juntamente com a geração de risco à integridade dessas pessoas que são jogadas às ruas e seus infortúnios. 
Ademais, pode-se inferir que outro argumento levantado contra as casas de prostituição inclina-se na direção de que tais locais seriam antros de exploração de mulheres (beirando a escravidão sexual), adolescentes e crianças (prostituição infantil). Entretanto, esse fundamento é vazio em sua essência, visto que a ausência de fiscalização destes locais se dá em razão da aceitação social, ou seja, falta nexo na repressão penal feminina diante da adequação do pensamento hodierno, em prol da igualdade de gênero. Destarte, a clandestinidade da ação é que alimenta os abusos sofridos por mulheres e crianças, sendo conveniente ao ente público não agir em tais circunstâncias, seja por pré-conceito (gravado no discurso de fundamentação) paternalista (moral) ou simplesmente por não vislumbrar relevância na defesa desses interesses. Fato é que se acaba por deixar desguarnecidas aquelas pessoas que efetivamente não poderiam se proteger, por crer na falsa moralidade como uma razão apta a sustentar um abuso do poder estatal (ROXIN, 2009, p. 20 - 25).

A regularização da conduta traz benefícios de diversos pontos de vista, já que trará uma fiscalização adequada (função administrativa), proteção à integridade da pessoa que presta o serviço (retira as mulheres do risco das ruas - segurança pública), respeita a disposição individual do ser humano (autonomia) e pode ser devidamente tributada como um estabelecimento (encargo tributário), ou seja, há uma movimentação diferenciada da máquina pública, mas em um sentido positivo e não moralmente depreciativo.

Diante do exposto, a justificativa exclusivamente moral encontra-se incompatível com a realidade social, com os ditames constitucionais (ainda mais diante de uma sociedade pluralista), humanos e criminais, sendo possível aferir, além dos benefícios da regulamentação das casas de prostituição, dentre as alternativas possíveis, o exercício do poder público de forma extralegal. Em outras palavras, as campanhas publicitárias, o apoio psicológico/financeiro dado a pessoas de baixa renda e a conscientização, já se mostraram em diversas situações soluções mais adequadas do que o uso excessivo da força do Estado. A imposição de uma moral coletiva, através de um discurso falacioso, é completamente inconstitucional - ofendendo as liberdades individuais e outros direitos humanos - 
assemelhando-se a uma tentativa de imposição religiosa a todos, não servindo como uma base jurídica minimamente respeitável (FELDENS, 2008, p. 36).

A defesa do posicionamento em prol da regulamentação da situação das casas de prostituição é somente um passo inicial no curso evolutivo do pensamento constitucionalizado do direito penal, visto que enquanto outras nações já regulamentaram a profissão de prostituta, como outras formas de exercício sexual (como os atores de filmes eróticos), alguns discutem esse processo ${ }^{9}$; no Brasil ainda permite-se que uma falsa moral paternalista seja utilizada para subjugar as mulheres que escolham tal atividade.

As ressalvas a tais afirmações são isoladas posições da jurisprudência, como as do Tribunal de Justiça do Rio Grande do Sul, o qual entendeu em diversos momentos a superação social desta vedação criminal $^{10}$, visualizando a distância entre a realidade e a manutenção da incriminação, sustentada por um discurso paternalista, utilizando-se da interpretação (com base em princípios e direitos humanos-fundamentais) para declarar a conduta atípica (descriminalização) (CARVALHO, 2007, p. 893 - 894). Apesar deste entendimento não ser compartilhado pelas elevadas cortes nacionais, como o Superior Tribunal de Justiça $^{11}$ (ou o Supremo Tribunal Federal), isso não reduz a sua contribuição como enfoque crítico-jurídico.

\footnotetext{
${ }^{9}$ Em recente matéria veiculada no site da Globo (2011) encontra-se o debate sobre a regulamentação da atividade na Irlanda, apenas como exemplo do assunto em comento.

${ }^{10}$ BRASIL. Rio Grande do Sul. Tribunal de Justiça. Casa de prostituição. Apelação Crime № 70023539554, Sétima Câmara Criminal, Tribunal de Justiça do RS, Relator: Alfredo Foerster, Porto Alegre, Julgado em 15 de maio de 2008. Ementa. Disponível em: <http://www.tjrs.jus.br>. Acesso em 15 de março 2009. Em sentido idêntico encontrar-se-á outros julgados, com exemplo o acórdão, BRASIL. Rio Grande do Sul. Tribunal de Justiça. Casa de prostituição. Apelação Crime № 7004144589, Sexta Câmara Criminal, Tribunal de Justiça do RS, Relator: Aymoré Roque Pottes de Mello, Porto Alegre, Julgado em 12 de maio de 2011. Ementa. Disponível em: <http://www.tjrs.jus.br>. Acesso em 09 de agosto 2011.
}

${ }^{11}$ BRASIL. Superior Tribunal de Justiça. Agravo Regimental - Casa de prostituição. AgRg no REsp 924750/RS, T6 - Sexta Turma, STJ, Relator: Maria Thereza de Assis Moura, Julgado em 15 de março de 2011. Ementa. Disponível em: <http://www.stj.jus.br>. Acesso em 09 de agosto 2011. "PENAL E PROCESSO PENAL. AGRAVO REGIMENTAL NO RECURSO ESPECIAL. NEGATIVA DE VIGÊNCIA AO ART. 229 DO CP (REDAÇÃO ANTIGA). CASA DE PROSTITUIÇÃO. DESCRIMINALIZAÇÃO. INOCORRÊNCIA. TIPICIDADE. REEXAME FÁTICO E PROBATÓRIO. IMPOSSIBILIDADE. SÚMULA 7/STJ. AGRAVO REGIMENTAL A QUE SE NEGA PROVIMENTO. 1. Esta Corte Superior tem entendimento no sentido de que não se pode falar em descriminalização pela ordem social do delito de casa de prostituição - artigo 229 do Código Penal. 2. É assente que cabe ao aplicador da lei, em instância ordinária, fazer um cotejo fático e probatório a fim de analisar a tipicidade da conduta descrita, sendo vedado a esta Corte revolver o arcabouço carreado aos autos, 
Dito isso, não se pode calar diante da inoperância legislativa ou da estagnação interpretativa, devendo-se bradar a bandeira de luta por um tratamento humano, digno e igualitário para as mulheres deste país, seja em relação à interrupção da gravidez ou às casas de prostituição, há imperiosidade de revisão do discurso e da postura adotada nas restrições de gênero no Brasil.

\section{CONSIDERAÇÕES FINAIS}

A complexidade que compõe a realidade moderna é capaz de sustentar uma pluralidade de situações e discursos diferentes; neste contexto caracterizado pela alta velocidade de difusão de informações e mutações, os direitos humanos e fundamentais servem a um papel diferenciado, a proteção de um suporte éticojurídico a compor o desenvolvimento do ser humano.

O contínuo processo de fortalecimento destas bases jurídicas para o crescimento adequado da sociedade somente foi possível graças ao empenho dos indivíduos em reclamarem melhores condições de vida e ao mesmo tempo ofertarem óticas renovadas sobre determinados problemas. Este foi o caso das questões de gênero, as quais tiveram, por meio dos movimentos sociais (exemplo: feminista), sua voz ouvida e representada nos debates sobre o real papel da mulher no mundo.

Destarte, a luta por efetivação de direitos é constante, portanto, algumas vedações perpetuadas pelo Estado, como ocorre no aborto e casas de prostituição, acabam por restringir direitos humanos e fundamentais de determinadas pessoas e classes sociais, especialmente neste caso de mulheres brasileiras. Não bastasse a ofensa a ditames constitucionais internos e de cunho internacional, há como suporte a tal postura um discurso punitivo paternalista, o qual além de contrapor-se a elementos constitucionais, constitui-se em verdadeiro mandamento antidemocrático, determinando um regimento moral repressivo de gênero (compactuando com um pensamento expansionista dos meios coercitivos estatais).

Portanto, com fulcro em ideais como dignidade, liberdade, igualdade e ofensividade, previstos constitucionalmente (materializando ainda mais concepções

ante a vedação do enunciado 7 da Súmula deste Superior Tribunal de Justiça. 3. Agravo regimental a que se nega provimento". 
internacionais), somados a inovações na esfera dos direitos humanos, como o princípio da autonomia reprodutiva, não se pode permitir a continuidade deste discurso falacioso, lesando permanentemente os interesses femininos. Diante disso, destaca-se aqui a imperiosidade do debate jurídico dessas questões de gênero, sob pena do Brasil ficar para trás na parcela mais importante do moderno desenvolvimento, o humano-social.

\section{REFERÊNCIAS}

\section{Bibliografia e outras fontes}

ANDRADE, Vera Regina Pereira de (A). A ilusão de segurança jurídica: do controle da violência à violência do controle penal. Porto Alegre: Livraria do Advogado, 2003.

(B). Sistema penal máximo x cidadania mínima: códigos da violência na era da globalização. Porto Alegre: Livraria do Advogado, 2003.

BARSTED, Leila Linhares. Direitos humanos e descriminalização do aborto. In: PIOVESAN, Flávia; SARMENTO, Daniel (Org.). Nos limites da vida: aborto, clonagem humana e eutanásia sob a perspectiva dos direitos humanos. Rio de Janeiro: Lumen Juris, 2007.

BITENCOURT, Cezar Roberto. Tratado de direito penal - parte geral. vol. 1. 8 ed. São Paulo: Saraiva, 2003.

BONAVIDES, Paulo. Teoria do estado. 5 ed. São Paulo: Malheiros, 2004.

CADEMARTORI, Sérgio. Estado de direito e legitimidade: uma abordagem garantista. Porto Alegre: Livraria do Advogado, 1999.

CANOTILHO, José Joaquim Gomes. Direito constitucional. 7 ed. Coimbra: Almedina, 2004.

CARVALHO, João Paulo Gavazza de Mello. Princípio constitucional penal da dignidade da pessoa humana. SCHMITT, Ricardo Augusto (org.). Princípios penais constitucionais: direito e processo penal à luz da constituição federal. Salvador: JusPodivm, 2007.

CARVALHO, Salo de. A sentença criminal como instrumento de descriminalização (o comprometimento ético do operador do direito na efetivação da constituição). In: NETO SOUZA, Cláudio Pereira de; SARMENTO, Daniel. A constitucionalização 
do direito: fundamentos teóricos e aplicações específicas. Rio de Janeiro: Lumen Juris, 2007.

COSTA, Marli. A transversalidade das políticas públicas na perspectiva de gênero. In: REIS, Jorge Renato dos; LEAL, Rogério Gesta. Direitos sociais e políticas públicas: desafios contemporâneos. Tomo 11. Santa Cruz do Sul: Edunisc, 2011.

DIAS, Maria Berenice. Conversando sobre justiça e os crimes contra as mulheres. Porto Alegre: Livraria do Advogado, 2004.

DWORKIN, Ronald. Domínio da vida: aborto, eutanásia e liberdades individuais. São Paulo: Martins Fontes, 2003.

ESTELLITA, Heloísa. Paternalismo, moralismo e direito penal: alguns crimes suspeitos em nosso direito positivo. Boletim publicação oficial do instituto brasileiro de ciências criminais - IBCCRIM. São Paulo: Revista dos Tribunais, ano 15. n. 179, 2007.

FARIA, Roberta Elzy Simiqueli de Faria. Autonomia da vontade e autonomia privada: uma distinção necessária. In: NAVES, Bruno Torquato de Oliveira; FIUZA, César; SÁ, Maria de Fátima Freire de (Coord.). Direito civil: atualidades II. Belo Horizonte: Del Rey, 2007.

FEINBERG, Joel. Harm to self: the moral limits of the criminal law. V. 3. Oxford: Oxford University Press, 1986.

FELDENS, Luciano. Direitos fundamentais e direito penal: garantismo, deveres de proteção, princípio da proporcionalidade, jurisprudência constitucional penal, jurisprudência dos tribunais de direitos humanos. Porto Alegre: Livraria do Advogado, 2008.

FERRAJOLI, Luigi. Direito e razão: teoria do garantismo penal. 3 ed. São Paulo: Revista dos Tribunais, 2010.

FERREIRA FILHO, Manoel Gonçalves. Direitos humanos fundamentais. São Paulo: Saraiva, 1998.

GADAMER, Hans-Georg, Verdade e método I: traços fundamentais de uma hermenêutica filosófica. 7 ed. Petrópolis: Vozes, 2005.

GLOBO. Disponível em <http://g1.globo.com/mundo/noticia/2011/09/posterestentam-profissionalizar-imagem-de-prostitutas-na-irlanda.html>. Acesso em 09 de setembro de 2011.

GOMES, Luiz Flávio. Princípio da ofensividade no direito penal. São Paulo: Revista dos Tribunais, 2002. 
GRONDIN, Jean. Introdução à hermenêutica filosófica. São Leopoldo: Unisinos, 1999.

JAKOBS, Günter; MELIÁ, Manuel Cancio. Direito penal do inimigo: noções e críticas. 4 ed. Porto Alegre: Livraria do Advogado, 2010.

KOSELLECK, Reinhart. Crítica e crise: uma contribuição à patogênese do mundo burguês. Rio de Janeiro: EDUERJ - Contraponto, 1999.

MILL, Stuart. On liberty. New York: Dover Publications, 2002.

MIRANDA, Jorge. Teoria do estado e da constituição. Rio de Janeiro: Forense, 2005.

MIRANDA, Marisa; VALLEJO, Gustavo (Compiladores). Darwinismo social y eugenesia en el mundo latino. Buenos Aires: Siglo XXI de Argentina Editores. 2005.

NUCCl, Guilherme de Souza. Código penal comentado. 7 ed. São Paulo: Revista dos Tribunais, 2007.

PÉRES-LUÑO. Antonio Enrique. Derechos humanos, Estado de derecho y constitución. 9 ed. Madrid: Tecnos, 2005.

PIAZZETA, Naele Ochoa. O princípio da igualdade no direito penal brasileiro: uma abordagem de gênero. Porto Alegre: Livraria do Advogado, 2001.

PIOVESAN, Flávia; GONÇALVES, Tamara Amoroso. Gênero no supremo tribunal federal. In: SARMENTO, Daniel; SARLET, Ingo Wolfgang (Coord.). Direitos fundamentais no supremo tribunal federal: balanço e crítica. Rio de Janeiro: Lumen Juris, 2011.

. Direitos sexuais e reprodutivos: aborto inseguro como violação aos direitos humanos. In: PIOVESAN, Flávia; SARMENTO, Daniel (Org.). Nos limites da vida: aborto, clonagem humana e eutanásia sob a perspectiva dos direitos humanos. Rio de Janeiro: Lumen Juris, 2007.

RODRIGUEZ, Javier Llobet. Derechos humanos y justicia penal. Heredia: Poder Judicial, Depto. De Artes Gráficas, 2007.

ROXIN, Claus. A proteção de bens jurídicos como função do direito penal. 2 ed. Porto Alegre: Livraria do Advogado, 2009.

SÁNCHEZ, Jesús-María Silva. A expansão do direito penal: aspectos da política criminal nas sociedades pós-industriais. 2 ed. São Paulo: Revista dos Tribunais, 2011. 
SARLET, Ingo Wolfgang. A eficácia dos direitos fundamentais: uma teoria geral dos direitos fundamentais na perspectiva constitucional. 10 ed. Porto Alegre: Livraria do Advogado, 2009.

Dignidade da pessoa humana e direitos fundamentais na constituição federal de 1988. 5 ed. Porto Alegre: Livraria do Advogado, 2008.

SARMENTO, Daniel. Legalização do aborto e Constituição. CAVALVANTE, Alcilene; XAVIER, Dulce (Organizadoras). Em defesa da vida: aborto e direitos humanos. São Paulo: Católicas pelo direito de decidir, 2006.

SCHWABE, Jürgen; MARTINS, Leonardo (Org). Cinqüenta anos de jurisprudência do tribunal constitucional alemão. Uruguay: Fundación Konrad-Adenauer, 2005.

SILVA, Virgílio Afonso da. A constitucionalização do direito. Os direitos fundamentais nas relações entre particulares. São Paulo: Malheiros, 2005.

STRECK, Lenio Luiz; MORAIS, José Luis Bolzan de. Ciência política e teoria geral do estado. 2 ed. Porto Alegre: Livraria do Advogado, 2001.

TORRES, José Henrique Rodrigues. Aborto inseguro: é necessário reduzir riscos. Revista brasileira de ciências criminais. São Paulo: Revista dos Tribunais, ano 15, n. 68, setembro - outubro, 2007.

VERÍSSIMO NETO, José. Arremesso de anão. Disponível em http://www.jusvox.com.br/mostraArtigo.asp?idNoticia=19. Acesso em: 11 de outubro de 2010.

VON HIRSCH, Andrew. Paternalismo direto: autolesões devem ser punidas penalmente? Revista brasileira de ciências criminais. São Paulo: Revista dos Tribunais, ano 15. n. 67, 2007.

ZAFFARONI, Eugenio Raúl. 0 inimigo no direito penal. 2 Ed. Rio de Janeiro: Revan, 2007.

\section{Jurisprudência}

BRASIL. Superior Tribunal de Justiça. Disponível em: <http://www.stj.jus.br>.

BRASIL. Tribunal de Justiça do Rio Grande do Sul. Disponível em <www.tjrs.jus.br>.

Recebido para publicação: 13/03/2012

Aceito para publicação: 09/08/2012 